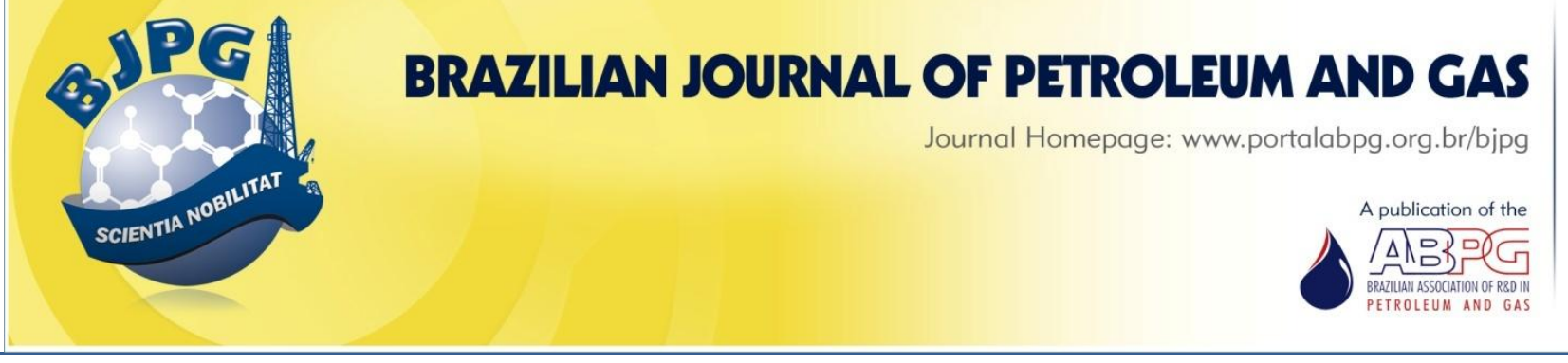

\title{
EVALUATING THE IMPACT OF PETROPHYSICAL IMAGES PARAMETERIZATION IN DATA ASSIMILATION FOR UNCERTAINTY REDUCTION
}

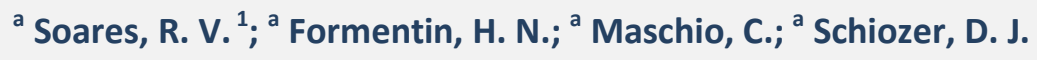 \\ a University of Campinas, Department of Energy, Division of Petroleum Engineering, Campinas - SP - Brazil
}

Received: 25.05.2019 / Revised: 07.11.2019 / Accepted: 11.11.2019 / Published on line: 20.12.2019

\begin{abstract}
Parameterization is a crucial step during uncertainty reduction of reservoir properties using dynamic data. It establishes the search space based on prior knowledge of the model and can have a significant influence on the final response. A less-appropriate parameterization might fail to have a reasonable representation of the reservoir and lead to models unable to predict the correct reservoir characteristics. Parameterization of petrophysical images (as facies, porosities, and permeabilities) plays an essential role during data assimilation processes due to the strong influence in fluid flow in the porous media. This work shows how important the parameterization of petrophysical images is and how a less-appropriate parameterization can affect history-matching and uncertainty reduction process. Using a benchmark case, we compare two parameterization techniques, one capable of treating all blocks in the model (distancedependent covariance localization), which is considered more appropriate, and one that considers a group of blocks under the same update rule (zonation) (less-appropriate). Results show that parameterization of petrophysical images has a high impact on the final response, and a less-appropriate parameterization, as the zonation, can generate higher data mismatches and fail to represent the real reservoir response. The analysis carried in this work quantifies and qualifies the impact of the parameterization of the petrophysical images in the data assimilation for the uncertainty reduction process.
\end{abstract}

\section{KEYWORDS}

data assimilation; parameterization; zonation; localization; ensemble-based methods

\footnotetext{
${ }^{1}$ To whom all correspondence should be addressed.

Address: University of Campinas, Department of Energy, Division of Petroleum Engineering, PO Box 6122, Campinas, São Paulo, Brazil.

ZIP Code: 13083-970 | e-mail: rsoares@cepetro.unicamp.br

doi:10.5419/bjpg2019-0021
} 


\section{INTRODUCTION}

Reservoir simulation models represent reservoir characteristics and behavior. Development and management of reservoirs are based on these models, and play a vital role in the upstream industry as they are responsible for field production and, consequently, for the generation of income. However, there is a large number of uncertainties in these models, and, as more data is collected, they can be used to update the models and reduce the uncertainties.

Data assimilation, also known as historymatching (HM) in the reservoir community, updates reservoir uncertain attributes to match simulated and historical data. As an inverse problem, the final answer (historical data) is known, and it has the goal of describing uncertain parameters that honor production data. In general, the lower the mismatch between simulated and observed data, the more reliable the simulation models are expected to be. The final goal of the process is to reduce uncertainty to improve the knowledge of the reservoir.

An essential step in data assimilation for uncertainty reduction is the parameterization of the uncertainties. Hutahaean et al. (2015) stated that parameterization restricts assumptions about the uncertainties into a defined search space based on geological and engineering knowledge. Therefore, the data assimilation process becomes more feasible in terms of computational efficiency. It is important to point out that parameterization is a crucial task in $\mathrm{HM}$ and, even if a reasonable data match is achieved, it does not mean that the resulting simulation models provide a good representation of the real reservoir. Therefore, it is desirable to carefully parameterize the problem and select an appropriate method to achieve both data match and reliable models.

Parameterization of petrophysical images, such as facies, porosities, and permeabilities is extremely important, as these results have a high impact on the fluid flow in the porous media. Additionally, since petrophysical image sizes depend on the model size, they can have high dimensions for large models, and the use of a parameterization technique becomes more important in reducing the dimension of the problem in such cases.
Zonation is a type of parameterization that identifies spatial zones and assigns either a constant value for a specific parameter or a multiplier responsible for modifying the parameters defined in a given zone (Khaninezhad \& Jafarpour, 2015). Hence, zonation parameterization makes use of a group of blocks under the same update rule - as uncertain attributes - instead of considering every grid block as uncertain. The zonation technique became usual for two main reasons. Firstly, it is simple and easily applicable. Secondly, some data assimilation methods, as the Iterative Discrete Latin Hypercube (IDLHC), are not able to deal with block-to-block correlation. Due to these reasons, several authors such as Agunwoke et al. (2004), Bertolini et al. (2015), Maschio and Schiozer (2016), and Almeida et al. (2018) applied the zonation technique in their studies.

However, one of the main challenges when using zonation is how to define regions. Some authors, such as Khaninezhad and Jafarpour (2015) and Oliveira et al. (2017), pointed out that this procedure generates geological discontinues in the model, affecting its consistency and leading HM procedures to fail in resulting good representation of the real reservoir.

To deal with this issue, Oliveira et al. (2017) proposed a workflow to integrate zonation and new geostatistical realization of the petrophysical images. Nevertheless, the proposed approach is time-consuming. Therefore, an alternative to this approach is to use history-matching methods capable of treating all gridblocks in the petrophysical images as uncertainties. A technique that has gained particular attention in the oil and gas $(O \& G)$ industry is the iterative ensemble-based methods.

Iterative ensemble-based methods use a crosscovariance matrix between the uncertainties and the data to update the uncertainties. They gained popularity in the O\&G industry because of their ability to deal with large models and ease of implementation (Evensen, 2009). Ensemble Smoother with Multiple Data Assimilation (ESMDA) (Emerick \& Reynolds, 2013) is an iterative ensemble-based method used by several authors, such as Morosov and Schiozer (2016), Soares et al. (2018), and Ranazzi and Sampaio (2019). 
Usually, for the application of ensemble-based in history match to be successful, the simple use of ES-MDA is not enough. Authors such as Aanonsen et al. (2009), Emerick and Reynold (2011), and Soares et al. (2018) suggested and proved that the use of covariance localization to avoid ensemble collapse and spurious correlation is very efficient. The most common covariance localization is the distance-dependent type, where a region around the wells is defined to constrain the uncertainty updates. The covariance localization tends to obtain more geologically consistent images as it generates smoother images and favors the preservation of geological continuity (Emerick \& Reynolds, 2011; Soares et al., 2018).

\subsection{Objective}

The objective of this work is to evaluate how a less-appropriate parameterization scheme can affect the quality of the reservoir representation after data assimilation. To achieve this objective, we used the ES-MDA, which is a well-established history-matching method capable of treating all grid blocks in the petrophysical images and compared the results using the zonation (lessappropriate) and the distance-dependent covariance localization (more appropriate).

The use of an ensemble-based method and covariance localization, which is proved to be very efficient, helps to point out explicitly the main differences compared to a less-appropriate parameterization (zonation) while reinforcing limitations of using this type of petrophysical image parameterization.

\section{ES-MDA AND DISTANCE-DEPENDENT COVARIANCE LOCALIZATION}

In the Ensemble Smoother with Multiple Data Assimilation (ES-MDA) methodology, developed by Emerick and Reynolds (2013), an initial parameterization is used as input to a Monte Carlo (MC) sampling to generate the initial set of scenarios. Then, the simulations are run, and, with the incorporation of the observed data, the analysis equation is computed. Analysis equation is defined as follows:

$$
m_{j}^{a}=m_{j}^{f}+\widetilde{C_{M D}^{f}}\left(\widetilde{C_{D D}^{f}}+\alpha_{i} C_{D}\right)^{-1}\left(d_{o b s, j}-d_{s i m, j}\right)
$$

where $m^{a}$ is the updated uncertain vector, $m^{f}$ is the prior uncertain vector, $d_{o b s}$ is the observed data, $\alpha$ is the inflation factor, $j$ is the scenario number, and $i$ the iteration number. In equations 2 to 5 , Emerick and Reynolds (2013) defined $\widetilde{C_{M D}^{f}}$ as the crosscovariance matrix between the uncertain vector and simulated data, $\widetilde{C_{D D}^{f}}$ as the auto-covariance of the simulated data, and $C_{D}$ as the error associated with $d_{o b s}$.

$\widetilde{C_{M D}}=\frac{1}{N e-1} \sum_{j=1}^{N e}\left(m_{j}^{f}-\overline{m^{f}}\right)\left(d_{s i m, j}-\overline{d_{s i m}}\right)^{T}$

$$
\begin{aligned}
\widetilde{C_{D D}^{f}} & =\frac{1}{N e-1} \sum_{j=1}^{N e}\left(d_{s i m, j}-\overline{d_{s l m}}\right)\left(d_{s i m, j}-\overline{d_{s i m}}\right)^{T} \\
C_{\mathrm{D}} & =\left[\begin{array}{cccc}
\sigma_{1}^{2} & 0 & \ldots & 0 \\
0 & \sigma_{2}^{2} & \ldots & 0 \\
\vdots & \vdots & \ddots & \vdots \\
0 & 0 & \ldots & \sigma_{N d}^{2}
\end{array}\right]
\end{aligned}
$$

$$
\sum_{i=1}^{N i} \frac{1}{\alpha_{i}}=1
$$

$\mathrm{Ni}$ is the total number of iterations, $\mathrm{Ne}$ the ensemble size (number of models), and $\sigma^{2}$ is the variance of a particular attribute. Note that $C_{D}$ is treated as a diagonal matrix due to the difficulty of estimating the correlation error for observed data, and $\alpha_{i}$ represents a weight assigned to each iteration (Emerick, 2016).

After the computation of updated uncertain attributes, the stopping criterion (usually the number of iterations) determines the end of the process.

Several authors (Aanonsen et al., 2009; Emerick, 2016; Morosov \& Schiozer, 2016) stated that ensemble-based methods underestimate the uncertainties, leading to an ensemble collapse. They suggested applying covariance localization to avoid this issue. One of the most used is the distance-dependent based type, and the formulation proposed by Gaspari and Cohn (1999): 


$$
\begin{aligned}
& \rho(\mathrm{h}, \mathrm{L})= \\
& =\left\{\begin{aligned}
-\frac{1}{4}\left(\frac{\mathrm{h}}{\mathrm{L}}\right)^{5}+\frac{1}{2}\left(\frac{\mathrm{h}}{\mathrm{L}}\right)^{4}+\frac{5}{8}\left(\frac{\mathrm{h}}{\mathrm{L}}\right)^{3}-\frac{5}{3}\left(\frac{\mathrm{h}}{\mathrm{L}}\right)^{2}+1, & 0 \leq h \leq L \\
\frac{1}{12}\left(\frac{\mathrm{h}}{\mathrm{L}}\right)^{5}-\frac{1}{2}\left(\frac{\mathrm{h}}{\mathrm{L}}\right)^{4}+\frac{5}{8}\left(\frac{\mathrm{h}}{\mathrm{L}}\right)^{3}+\frac{5}{3}\left(\frac{\mathrm{h}}{\mathrm{L}}\right)^{2}-5\left(\frac{\mathrm{h}}{\mathrm{L}}\right)+4-\frac{2}{3}\left(\frac{\mathrm{h}}{\mathrm{L}}\right)^{-1}, & L \leq h \leq 2 L \\
0, & h>2 L
\end{aligned}\right.
\end{aligned}
$$

where $\rho$ is the localization value, $h$ is the Euclidian distance between the point where the data were observed (e.g. position of production and injection wells) and any grid cell, and $L$ is the critical length defined by the user. Then, $\rho$ is introduced in Equation 1 through a Schur product (element by element multiplication) described in Equation 7.

$\left.m_{j}^{a}=m_{j}^{f}+\rho \circ \widetilde{\left(C_{M D}^{f}\right.}\left(\widetilde{C_{D D}^{f}}+\alpha_{i} C_{D}\right)^{-1}\right)\left(d_{o b s, j}-d_{s i m, j}\right)$

Physically, distance-dependent covariance localization represents a constraint-based on spatial regions (usually defined according to the wells), where the uncertainties within a region are updated based on the data from the specific well. Figure 1 shows an example of the distancedependent localization function using Equation 6. It is a smooth function: close to the wells, $\rho$ has higher values, indicating that the closer an uncertain parameter is from the well, the more affected by data from this specific well it will be. Therefore, this technique avoids spurious longdistance correlations (Aannonsen et al., 2009).

Soares et al. (2018) defined an approach to determine the spatial regions in distancedependent localization based on streamlines. The idea was to select blocks for a region based on the largest area covered by streamlines during the historical period.

However, distance-dependent covariance localization only considers petrophysical parameters (Emerick, 2016; Soares et al., 2018); therefore, scalar parameters, such as water relative permeability or rock compressibility, might still have an excessive reduction on their variability.

Soares et al. (2019) proposed two methodologies to update scalar uncertainties and avoid their ensemble collapse: Binary Correlation Coefficient (BCC) and Full Correlation Coefficient (FCC). In both approaches, they used correlation coefficients $(R)$ between simulated data and scalar uncertainty shown by Equation 8 .

$R_{a b}=\frac{C_{a b}}{\sqrt{C_{a a} * C_{b b}}}$

where $a$ is the difference between observed and simulated data represented by the selected objective function, $b$ is an uncertainty (for example, rock compressibility), and $C$ (Equation 9) is the covariance between $a$ and $b$.

$C_{a b}=\frac{1}{N e-1} \sum_{j=1}^{N e}\left(a_{j}-\bar{a}\right)\left(b_{j}-\bar{b}\right)$

Here, $\bar{a}$ and $\bar{b}$ are the mean value of $a$ and $b$, respectively.

In BCC, they applied a threshold value to determine which scalar uncertainty affects the production data the most. If the correlation value is higher than the threshold value, $\rho$ regarding a specific uncertainty and a production data would receive a value of one, and zero otherwise. For FCC, $\rho$ receives the absolute value calculated by Equation 8, which assigns a proper weight for each observed data and scalar uncertainty.

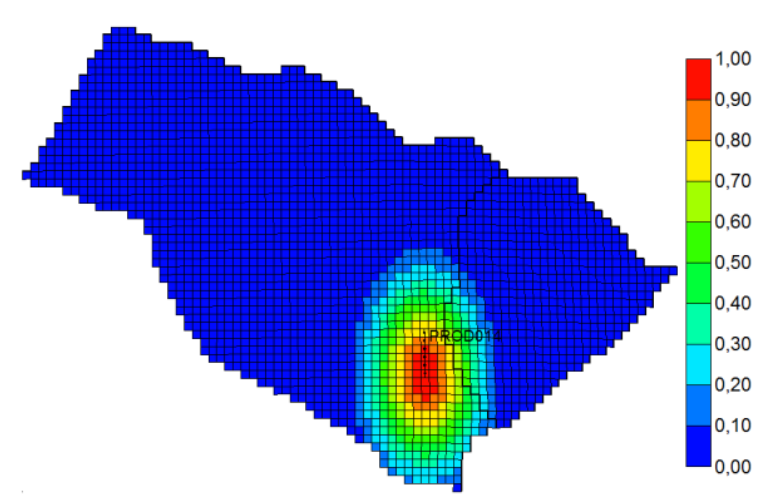

Figure 1. Example of distance-dependent localization using Gaspari and Cohn's (1999) formulation (Soares et al., 2018). 


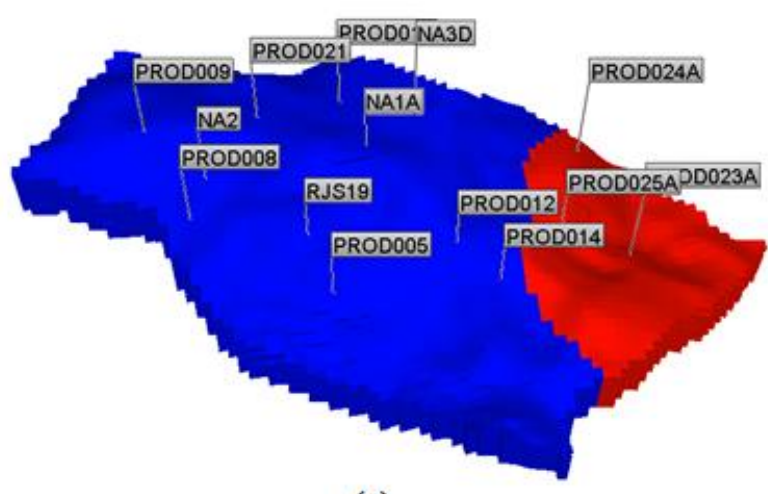

(a)

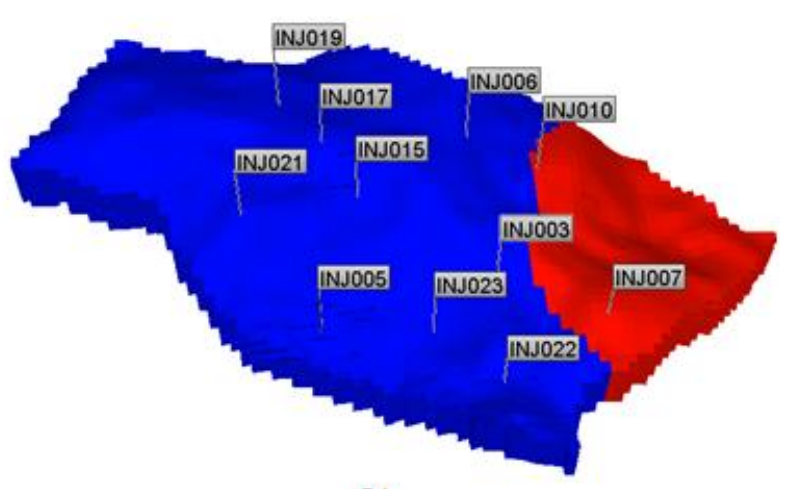

(b)

Figure 2. Main block of UNISIM-I-H in blue and East block in red. Producer wells (a) and injector wells (b).

In summary, ES-MDA is a method capable of dealing with correlations between every block in a reasonable computational effort. Additionally, the use of distance-dependent covariance localization and FCC/BCC to update petrophysical and scalar uncertainties enables the generation of lower data mismatches between simulated and observed data, preserving geological continuity and avoiding ensemble collapse.

\section{METHODOLOGY AND APPLICATION}

To evaluate the impact of the parameterization of the petrophysical images, we divided this work into two parts: (1) use of ES-MDA with distancedependent covariance localization (more appropriate parameterization); and (2) use of ESMDA with the zonation technique (less-appropriate parameterization).

The model selected for this study is a benchmark case based on the consolidated sandstone reservoir from the Namorado field in the Campos Basin, Brazil. Avansi and Schiozer (2015) developed a high-fidelity model with about 3.5 million grid cells as the reference model (UNISIM-I-R) to represent the real field. The UNISIM-I-H is a model with lower fidelity than the UNISIM-I-R, developed for testing and comparing history matching methodologies. Botechia et al. (2018), Santos et al. (2018), and Silva et al. (2017) also used this benchmark and proved its potential for testing new methodologies.

The model has two production areas (main area and east block - Figure 2) divided by a sealing fault.
The production strategy contains 14 producer wells (ten horizontal wells located at the top of the reservoir and four vertical wells) and 11 injector wells located at the bottom of the reservoir. The original oil in place is 130 million $\mathrm{m}^{3}$; oil density is $28^{\circ} \mathrm{API}$ : the fluid is represented by a black-oil simulator. We used the IMEX from Computing Modelling Group (CMG) as the simulation software.

UNISIM-I-H is discretized in $81 \times 58 \times 20$ grid cells, each of them measuring $100 \times 100 \times 8 \mathrm{~m}$. Data from reference model UNISIM-I-R covers 11 years of historical period (noise added) and an additional period to evaluate the predictability of scenarios resulting from the HM procedures, summing a total time of 30 years.

\subsection{ES-MDA with distance-dependent covariance localization (ES-MDA (L))}

The uncertain parameters defined for ES-MDA with distance-dependent covariance localization (ES-MDA (L)) are of two classes: (a) Petrophysical uncertain parameters present a single value for each grid cell, such as porosity and permeability; (b) Scalar uncertainties provide a single parameter value for the entire model or only part of it. Table 1 introduces the initial ranges for the considered uncertainties with their uniformly distributed discretized levels.

The covariance distance-dependent localization used to update petrophysical uncertainties corresponds to Gaspari and Cohn (1999) formulation for $\rho$ (Equation 6). In addition, we delineated the influence region of each production data based on streamlines (Soares et al., 2018). To 
Table 1. Uncertain parameters defined for ES-MDA(L).

\begin{tabular}{|c|c|c|c|c|c|}
\hline Type & Uncertainty & Unit & Minimum & Maximum & $\begin{array}{l}\text { Number of } \\
\text { levels }\end{array}$ \\
\hline \multirow{4}{*}{ Petrophysical } & Porosity & - & 0.00 & 0.39 & - \\
\hline & Permeability I ( $\left.k_{x}\right)$ & $\mathrm{mD}$ & 1 & 5,000 & - \\
\hline & Permeability J $\left(k_{\mathrm{y}}\right)$ & $\mathrm{mD}$ & 1 & 5,000 & - \\
\hline & Permeability Z $\left(\mathrm{k}_{\mathrm{z}}\right)$ & $\mathrm{mD}$ & 1 & 2,500 & - \\
\hline \multirow{6}{*}{ Scalars } & Rock compressibility (CPOR) & $\left(\mathrm{kgf} / \mathrm{cm}^{2}\right)^{-1}$ & $1.0 * 10^{-5}$ & $9.6 * 10^{-5}$ & 30 \\
\hline & $\begin{array}{l}\text { Water relative permeability } \\
\left(k_{\mathrm{rw}}\right)\end{array}$ & - & - & - & 30 \\
\hline & $\begin{array}{l}\text { Oil Compressibility- PVT table } \\
\text { - East block }\end{array}$ & $\left(\mathrm{kgf} / \mathrm{cm}^{2}\right)^{-1}$ & $1.40 * 10^{-3}$ & $1.62 * 10^{-3}$ & 30 \\
\hline & $\begin{array}{l}\text { Factor associated to oil } \\
\text { Viscosity- PVT table - East } \\
\text { block }\end{array}$ & $\left(\mathrm{kgf} / \mathrm{cm}^{2}\right)^{-1}$ & $2.50 * 10^{-4}$ & $50.00 * 10^{-4}$ & 30 \\
\hline & $\begin{array}{l}\text { Water-oil contact (DWOC) - } \\
\text { East block }\end{array}$ & $\mathrm{m}$ & 3,169 & 3,179 & 30 \\
\hline & Well index factor $\left(W_{\mathrm{ff}}\right)$ & - & 0.6 & 1.4 & 30 \\
\hline
\end{tabular}

update scalar parameters, we selected the Full Correlation Coefficient (FCC) methodology because it provided a better data match and helped to maintain the variability of the final answer when presented by Soares et al. (2019).

The other characteristics of the ES-MDA method follow the work of Soares et al. (2018), and we used 450 models per ensemble, six iterations, constant inflation factor and $C_{D}=10 \%$. Moreover, it assimilated oil rate $\left(q_{o}\right)$, produced water rate $\left(q_{w}\right)$, injected water rate $\left(q_{\text {wi }}\right)$, and bottom-hole pressure
(BHP) for producer and injector wells.

\subsection{ES-MDA with zonation (multipliers) - ES-MDA (M)}

In this part of the work, the parameterization comprises the thirteen regions suggested by Maschio and Schiozer (2016) for the UNISIM-I-H model. Figure 3 depicts all the regions and two cross-sections, demonstrating that the regions were the same for all layers.

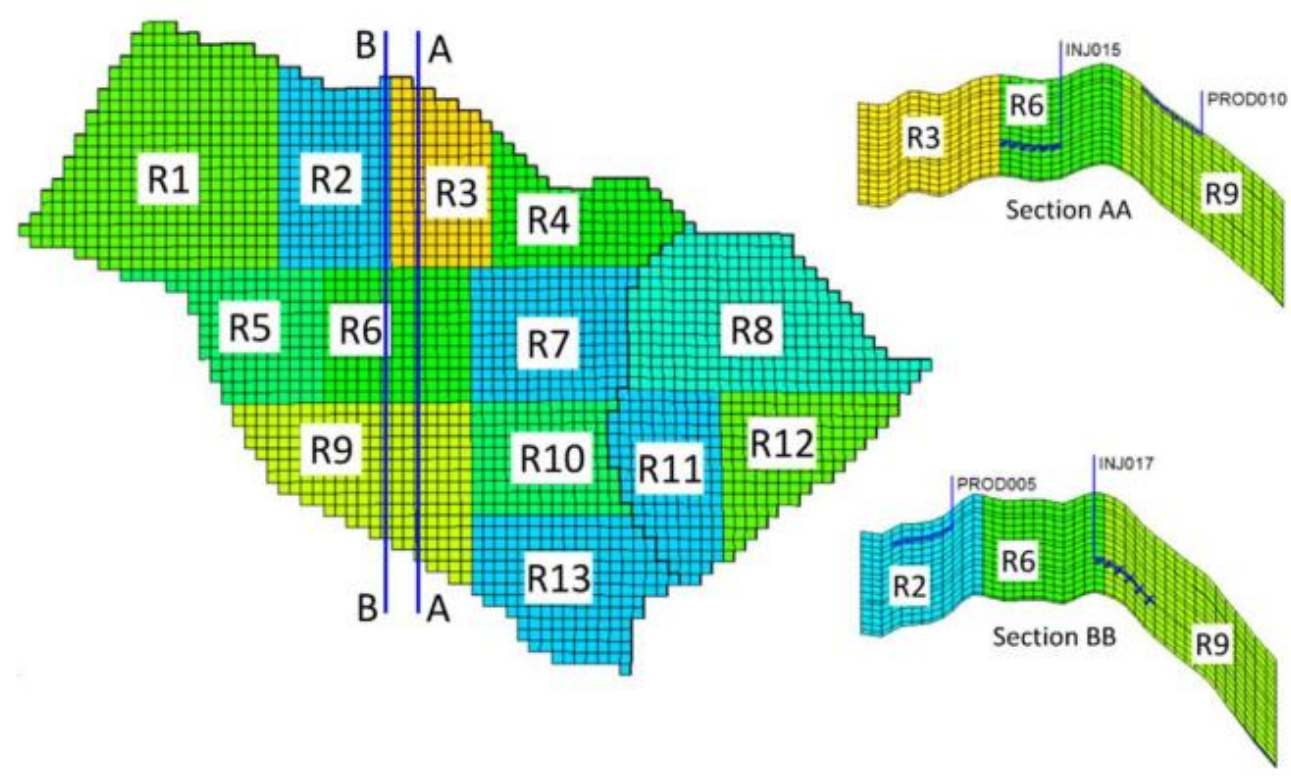

Figure 3. UNISIM-I-H thirteen regions and two cross-sections (Maschio \& Schiozer, 2016). 
Table 2. Scalar uncertainties and parameterizations for ES-MDA.

\begin{tabular}{|c|c|c|c|}
\hline Uncertainty & Minimum & Maximum & $\begin{array}{c}\text { Number of } \\
\text { levels }\end{array}$ \\
\hline Porosity Multipliers (13) & 0.75 & 1.25 & 10 \\
\hline$A$ & 0.135 & 0.175 & 10 \\
\hline B & -0.4 & 1.1 & 10 \\
\hline $\begin{array}{l}\text { Permeability Z multipliers (mkz) } \\
\text { (13) }\end{array}$ & 0.1 & 0.5 & 21 \\
\hline $\begin{array}{l}\text { Rock compressibility (CPOR) } \\
\qquad\left(\mathrm{kgf} / \mathrm{cm}^{2}\right)^{-1}\end{array}$ & $1.0 * 10^{-5}$ & $9.6 * 10^{-5}$ & 30 \\
\hline $\begin{array}{l}\text { Water relative permeability } \\
\left(\mathrm{k}_{\mathrm{rw}}\right) \text { (dimensionless) }\end{array}$ & - & - & 30 \\
\hline $\begin{array}{c}\text { Oil Compressibility }\left(\mathrm{kgf} / \mathrm{cm}^{2}\right)^{-1}- \\
\text { PVT table - East block }\end{array}$ & $1.40 * 10^{-3}$ & $1.62 * 10^{-3}$ & 30 \\
\hline $\begin{array}{l}\text { Factor associated to oil } \\
\text { Viscosity }\left(\mathrm{kgf} / \mathrm{cm}^{2}\right)^{-1}-\text { PVT table } \\
\text { - East block }\end{array}$ & $2.50 * 10^{-4}$ & $50.0 * 10^{-4}$ & 30 \\
\hline $\begin{array}{c}\text { Water-oil contact (DWOC) (m) - } \\
\text { East block }\end{array}$ & 3,169 & 3,179 & 30 \\
\hline Well index factor $\left(W_{\mathrm{ff}}\right)$ & 0.6 & 1.4 & 30 \\
\hline
\end{tabular}

Defined according to the influence area of each pair producer-injector, each of these regions is associated with a porosity multiplier as uncertain parameters (Table 2). Equation 10 relates porosity to horizontal permeability $\left(\mathrm{k}_{\mathrm{x}}\right.$ and $\mathrm{k}_{\mathrm{y}}$ ), enabling the preservation of a correlation between these uncertain properties.

$k_{x}=10^{100 * A * \emptyset-B}$

Porosity is $\varnothing, A$ and $B$ are unique uncertain parameters (Table 2 ) in the whole reservoir model. With that, we expect to obtain a fairer comparison between ES-MDA (M) and ES-MDA (L), because ESMDA (L) updates petrophysical uncertainties based on properties of the entire model.

We calculate vertical permeability $\left(k_{z}\right)$ with independent multipliers $(m k z)$ for each region through Equation 11.

$k_{z}=m k z * k_{x}$

Table 2 summarizes the initial parameterization for the application ES-MDA (M). All uncertainties are scalar, and the FCC was applied, similarly to the parameterization for ES-MDA (L).

We highlight that this approach limits the ES-
MDA technique in its ability to deal with block-toblock correlation and the use of distancedependent covariance localization. However, this is a novel adapted application for the objective of identifying the main limitations and applicability of a less-appropriate parameterization (zonation).

\subsection{Analysis of the result}

We perform a systematic comparison between the situations described in sections 3.1 and 3.2, aiming to assess the impact of the petrophysical images parameterization in the history-matching process. We quantify the difference in the behavior of the resulting scenarios following the sequence proposed by Soares et al. (2018):

(1) Check data match based on the Normalized Quadratic Deviation with Sign (NQDS);

(2) Assess the uncertainty reduction;

(3) Select the acceptable models based on the data mismatch and a defined value of NQDS;

(4) Simulate production forecast of accepted scenarios to check if they encompass the reference response.

NQDS is mathematically defined as: 
Table 3. Tolerance and constant used to compute NQDS.

\begin{tabular}{ccc}
\hline Variable & Tolerance (tol) & Constant (Cons) \\
\hline$q_{o}$ & 0.10 & $0 \mathrm{~m}^{3} /$ day \\
$q_{w}$ & 0.10 & $20 \mathrm{~m}^{3} /$ day \\
$q_{w i}$ & 0.05 & $0 \mathrm{~m}^{3} / \mathrm{day}$ \\
BHP & 0.10 & $0 \mathrm{kgf} / \mathrm{cm}^{2}$ \\
\hline
\end{tabular}

$N Q D S=\frac{\sum_{k=1}^{N d}\left(d_{s i m, k}-d_{o b s, k}\right)}{\left|\sum_{k=1}^{N d}\left(d_{s i m, k}-d_{o b s, k}\right)\right|} *$

$* \frac{\sum_{k=1}^{N d}\left(d_{s i m, k}-d_{o b s, k}\right)^{2}}{\sum_{k=1}^{N d}\left(t o l * d_{o b s, k}+C o n s\right)^{2}}$

where $d_{\text {sim }}$ is the simulated data, $d_{o b s}$ is the observed (historical) data, tol is a tolerance determined by the user as a percentage of $d_{\text {obs }}$, Cons is a constant also defined by the user to avoid division by zero, and $N d$ is the number of historical data point.

For both approaches, we used the same values for the tolerance and constant values used in NQDS formulation. Table 3 depicts these values.
We also present maps of porosity and permeability of the reservoir to verify geological consistency and continuity. Combining the analysis of quality indicators (NQDS), scenarios forecasting, and petrophysical maps provide relevant insights for a comparative reservoir study.

\section{RESULTS AND DISCUSSION}

We analyzed the results through the sequence emphasized in section (3.3). Both ES-MDA(L) and (M) resulted in similar NQDS values for oil rate $\left(q_{0}\right)$ for all wells (Figure 4a). Nevertheless, in Figure 4b, NQDS of water production rate $\left(q_{w}\right)$ presented a higher mismatch for ES-MDA (M), with zonation,

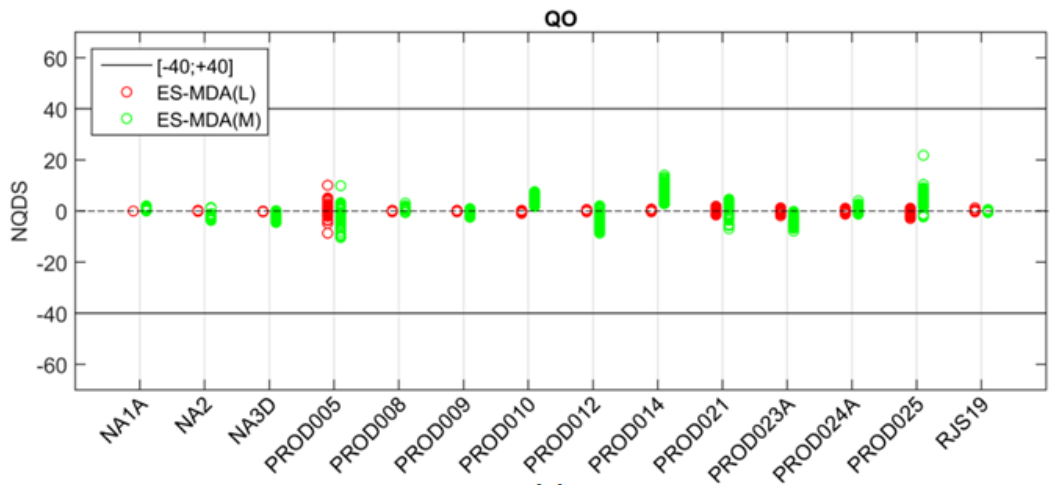

(a)

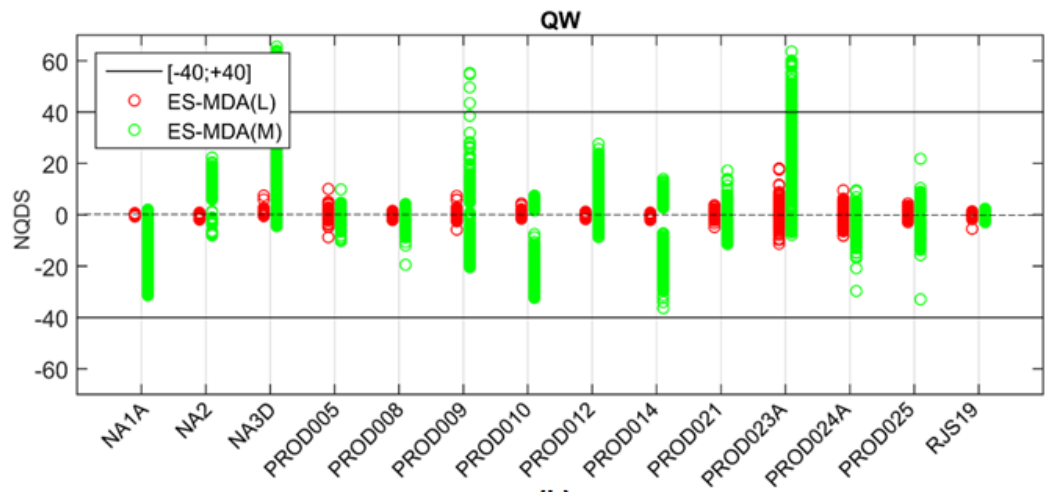

(b)

Figure 4. NQDS: oil rate (a); water rate (b). 


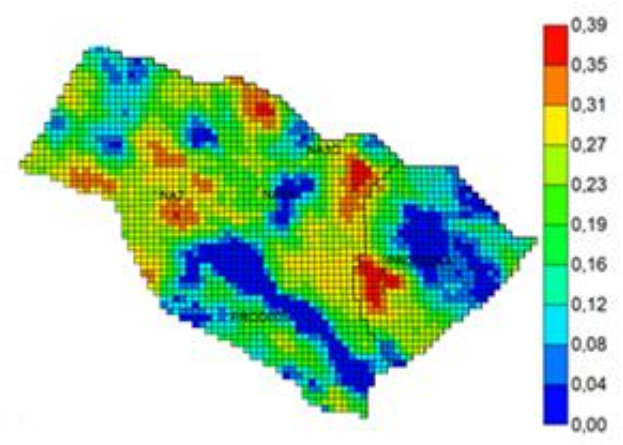

(a)

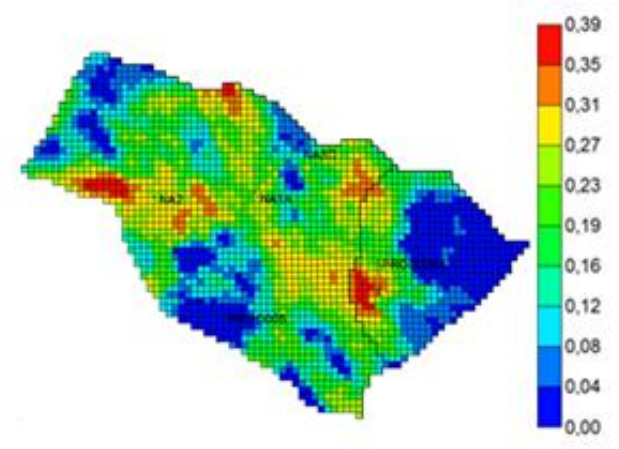

(b)

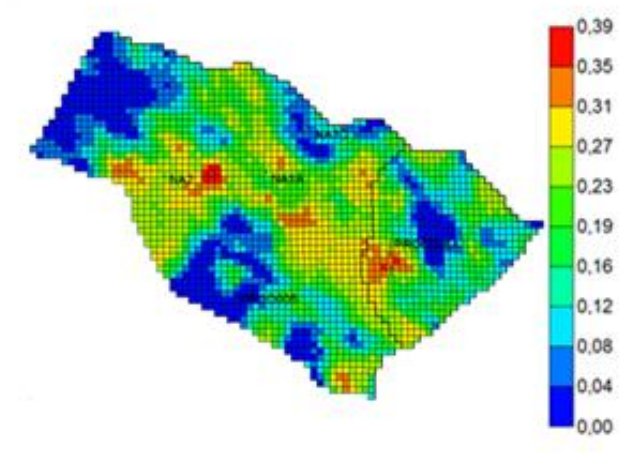

(c)

Figure 5. ES-MDA (L) porosity - layer 3: Scenario \#1 (a); Scenario \#344 (b); Scenario \#379 (c).

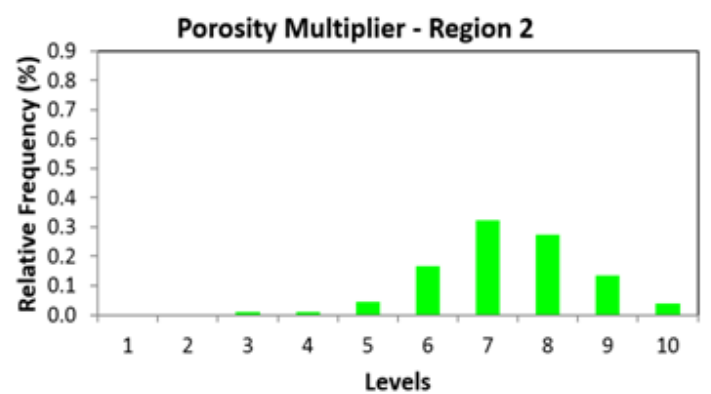

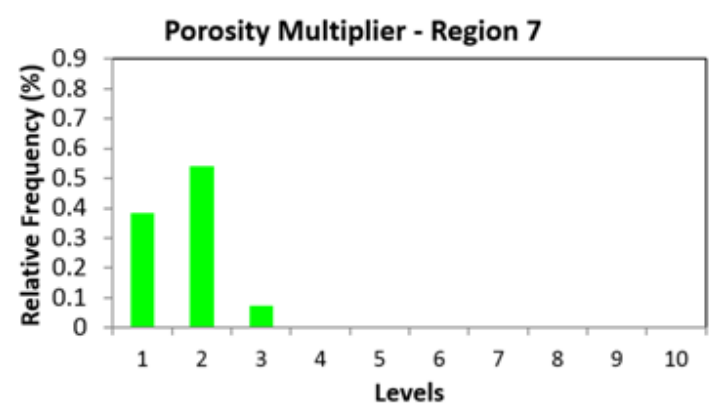

(b)

(a)

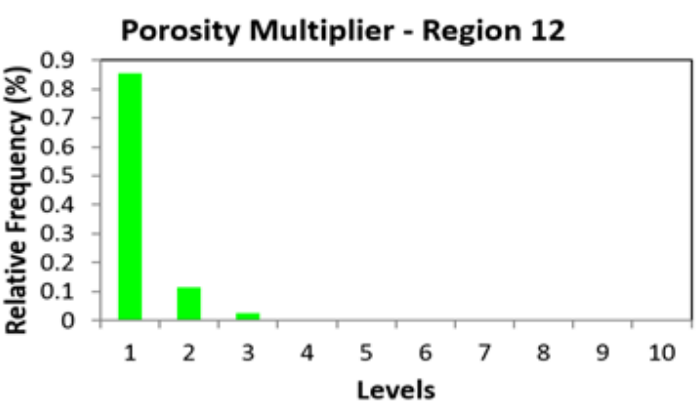

(c)

Figure 6. Porosity multiplier: Region 2 (a); Region 7 (b) and Region 12 (c).

than ES-MDA(L), especially for wells NA3D and PROD023A.

Regarding the petrophysical properties, Figure 5 shows that ES-MDA (L) generated porosity images with a high degree of variability. For instance, the east block for scenario \#344 (Figure 5b) showed lower porosity values than scenarios \#1 and \#379 (Figure $5 \mathrm{a}$ and $\mathrm{c}$, respectively). Despite the difference in the images, all scenarios presented small data mismatches.

Figure 6 shows the histogram of porosity multiplier for three different regions $(2,7$, and 12$)$. 
Except for region 2, all other regions presented a trend towards lower values of the multiplier parameters. Figure 7 shows region 2 achieving high values of porosity (about 0.35) for all different scenarios and a clear geological discontinuity around region 2 (highlighted by the black ellipse). We also noticed that the posterior values converged for similar values, generating images very alike, as shown in Figure 7.

However, a comparison between the average porosity for ES-MDA (L) among all scenarios and a random scenario from ES-MDA (M) (Figure 8) indicates some similarities (red ellipses in the east and central part of the reservoir). It demonstrates that the parameterization techniques have
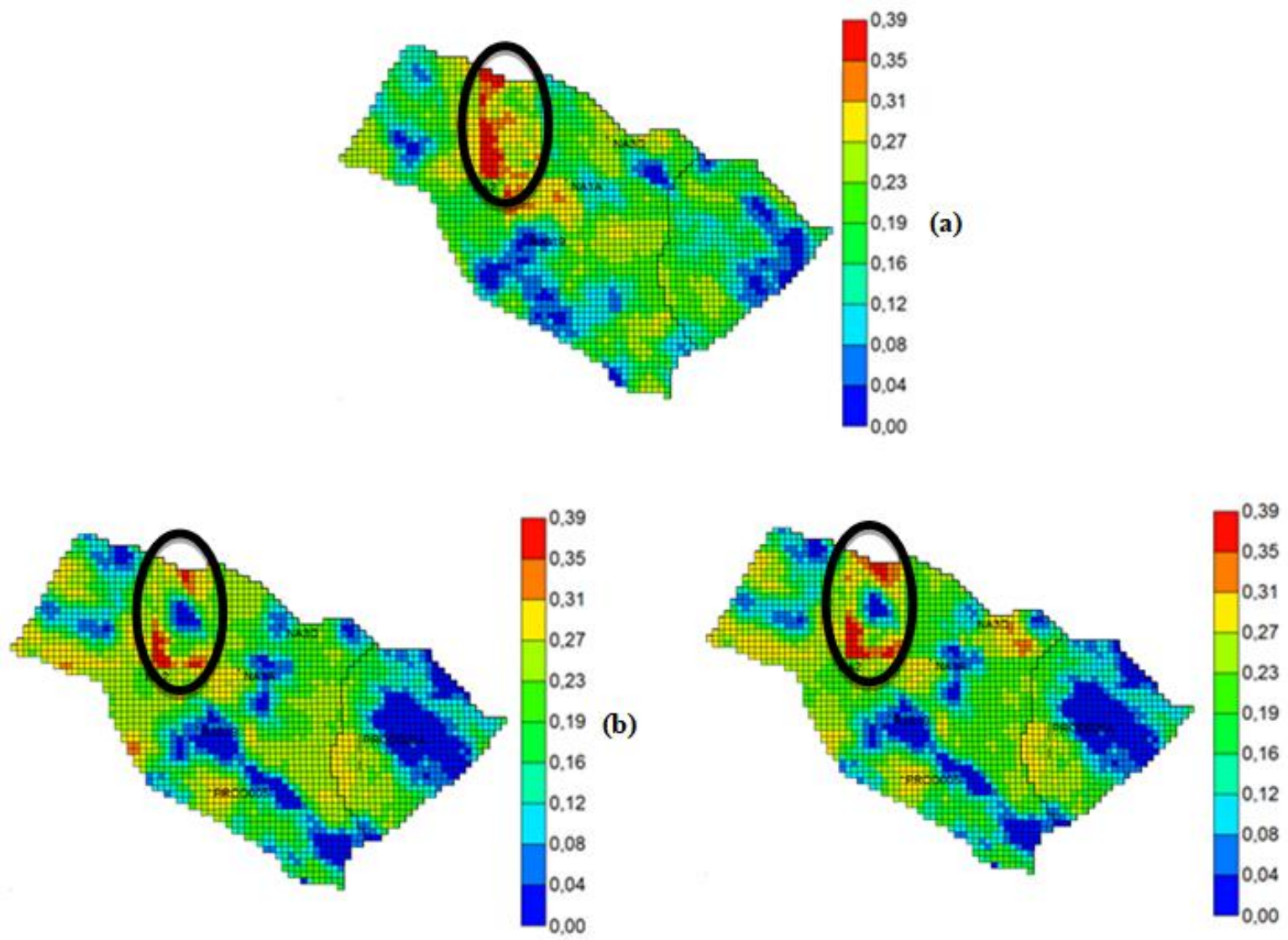

(c)

Figure 7. ES-MDA (M) porosity - layer 3: Model \#1(a); Model \#344(b); and Model \#379 (c).

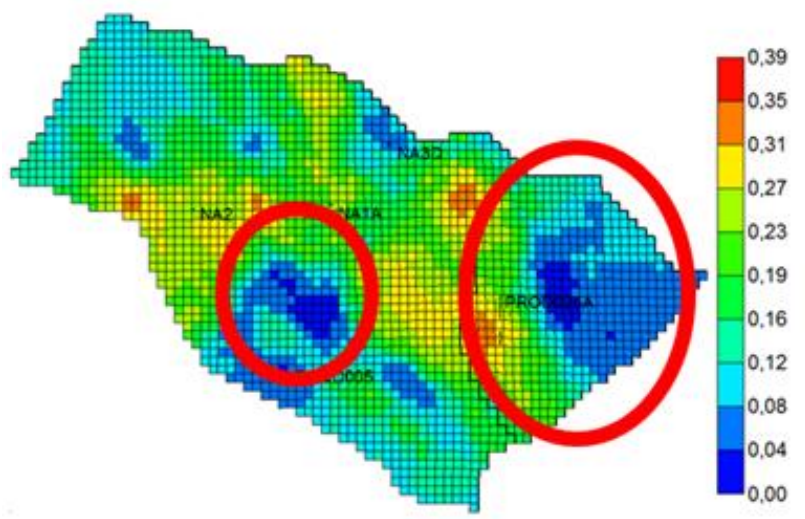

(a)

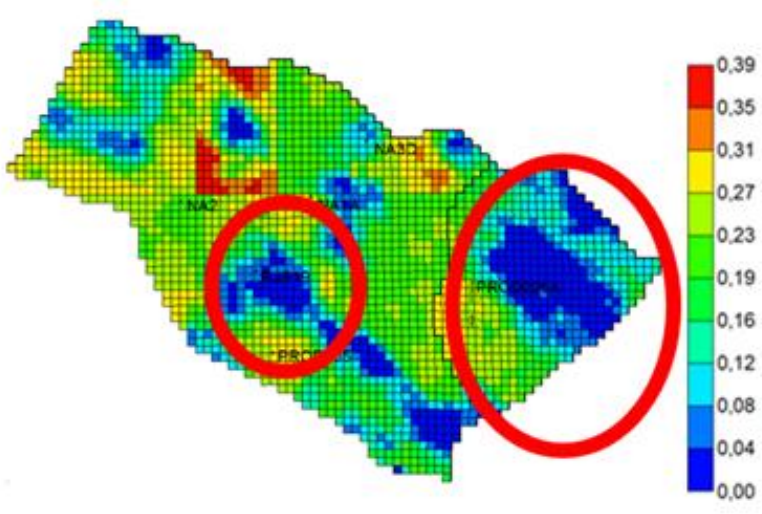

(b)

Figure 8. Comparison between average porosity distribution - layer 3: ES-MDA (L) (a); and ES-MDA (M) (b). 


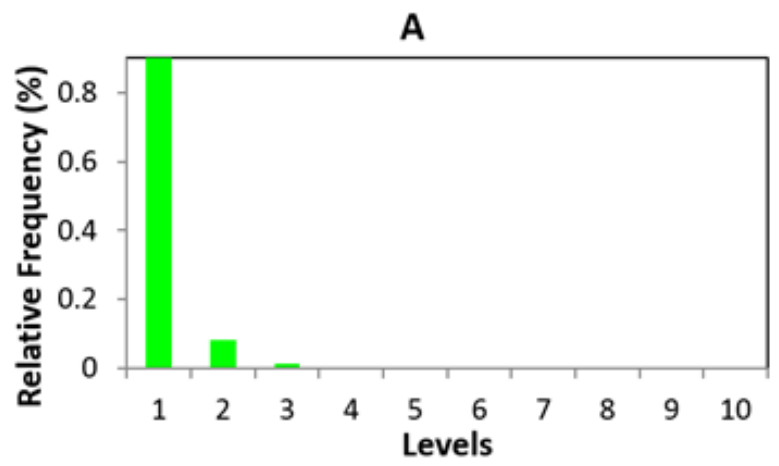

(a)

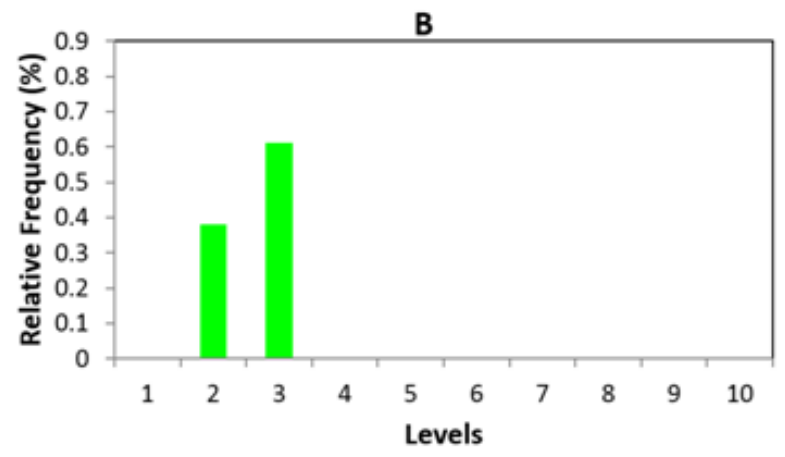

(b)

Figure 9. Permeability equation (ES-MDA (M)): A (a) and B (b).

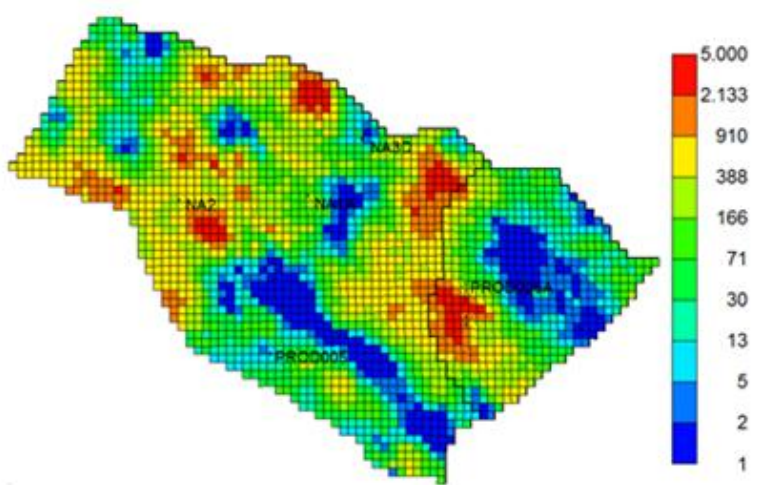

(a)

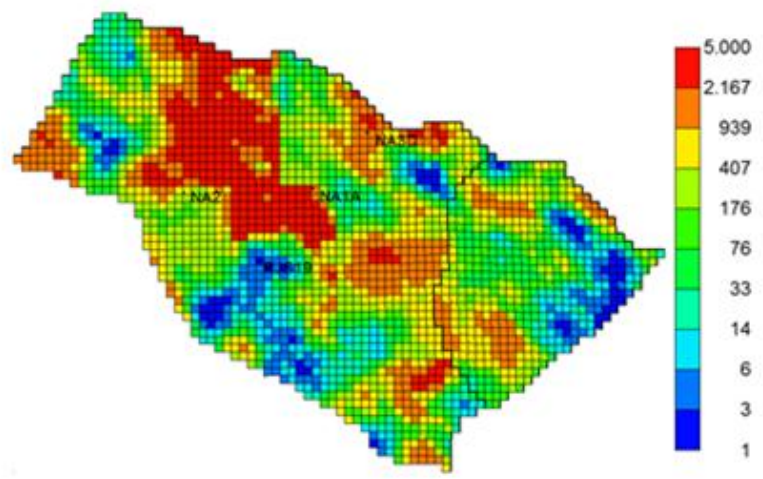

(b)

Figure 10. Horizontal permeability - layer 3 - Scenario \#1: ES-MDA (L) (a) and ES-MDA (M) (b).

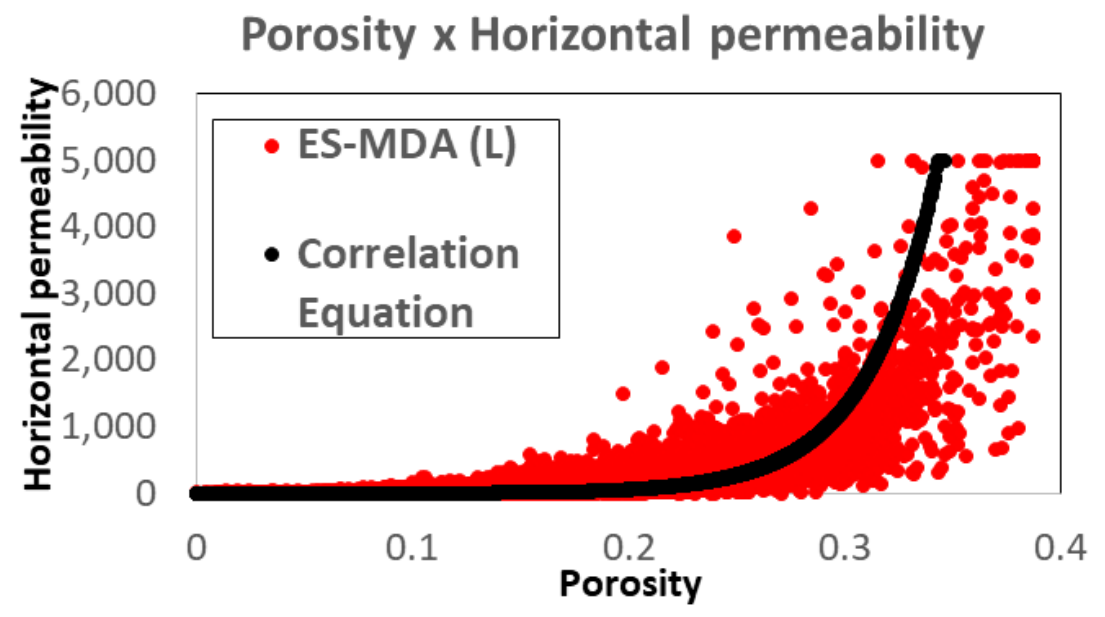

Figure 11. Porosity and horizontal permeability for ES-MDA (L).

comparable correlations for specific regions.

The horizontal permeability resulted in the same pattern mentioned previously, where for ESMDA (L) the final images showed a higher variability among the scenarios than ES-MDA (M), from which posterior distributions of $A$ and $B$ are concentrated in two levels (Figure 9a and b). In addition, Figure 10 depicts that the low values of $A$ and $B$ produced images with higher permeability than ES-MDA (L). 
Comparing both approaches, we verified that ES-MDA(M) converged for values of $A$ around 0.135 and $B$ around 0.05. Nevertheless, plotting the correlation between horizontal permeability and porosity for ES-MDA(L) in Figure 11, it is possible to see that the approaches converged for different values, as $A$ and $B$ values were about 0.135 and 0.933 for the latter case.

Figures $12 \mathrm{a}$ and $\mathrm{b}$ are examples indicating that the vertical permeability for ES-MDA(M) resulted in higher $k_{z}$ values than ES-MDA(L). The higher values impaired the water rate data match showed in

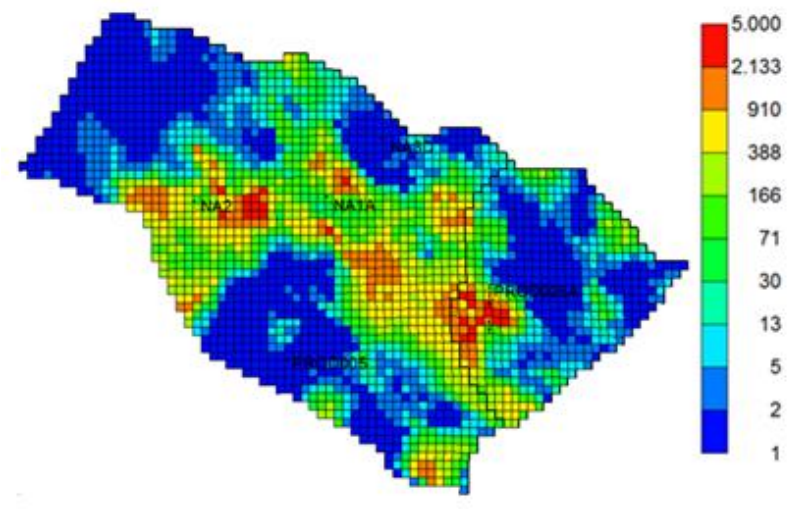

(a)

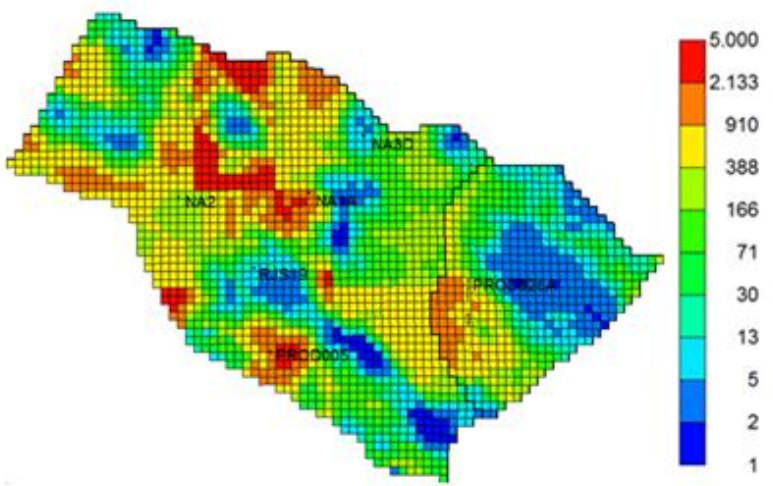

(b)

Figure 12. Vertical permeability: Scenario \#1: ES-MDA (L) (a) and ES-MDA (M) (b).

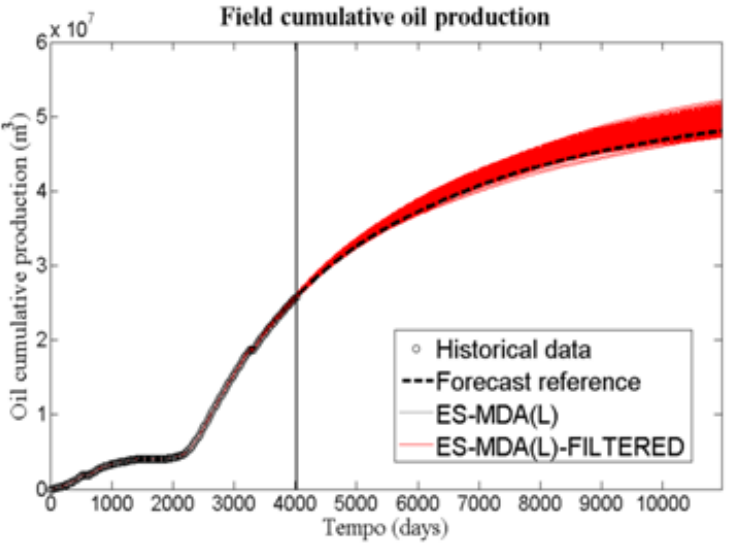

(a)

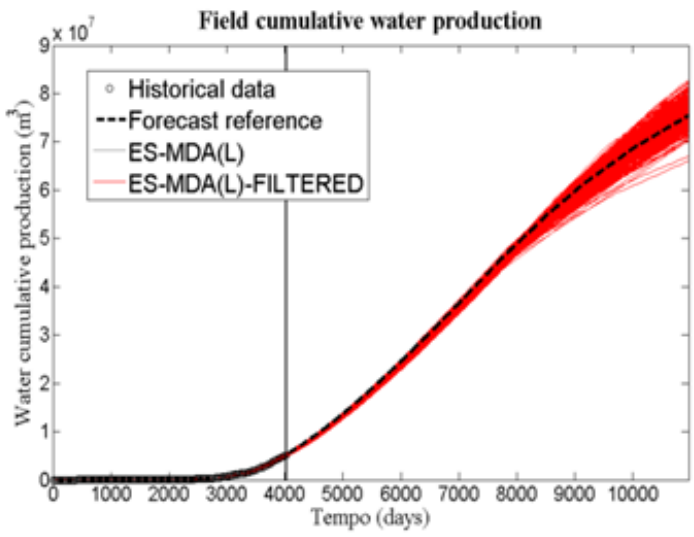

(c)

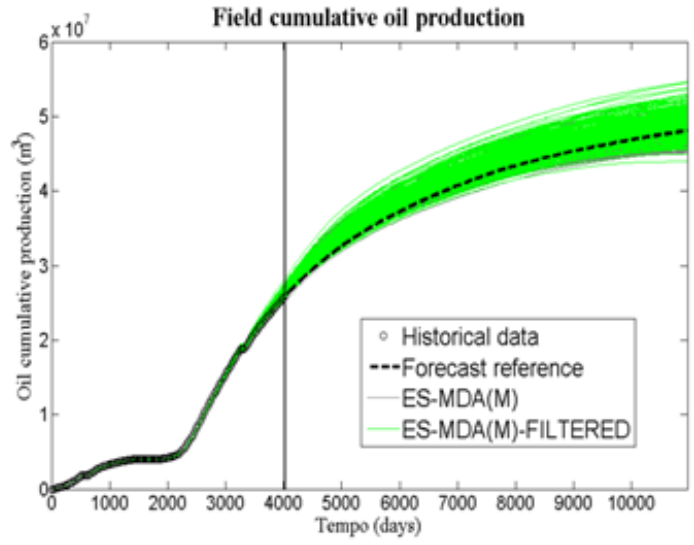

(b)

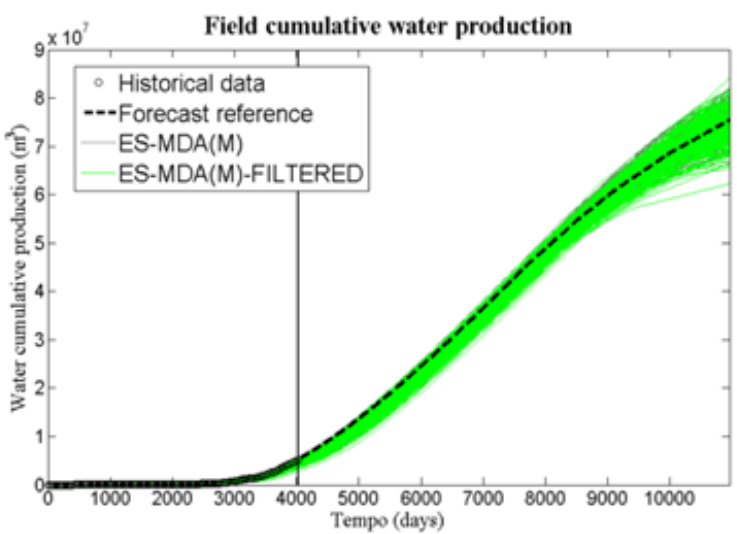

(d)

Figure 13. Cumulative production forecast: Field cumulative oil production - ES-MDA (L) (a); Field cumulative oil production ES-MDA (M) (b); Field cumulative water production - ES-MDA (L) (c); and Field cumulative water production - ES-MDA (M) (d). 


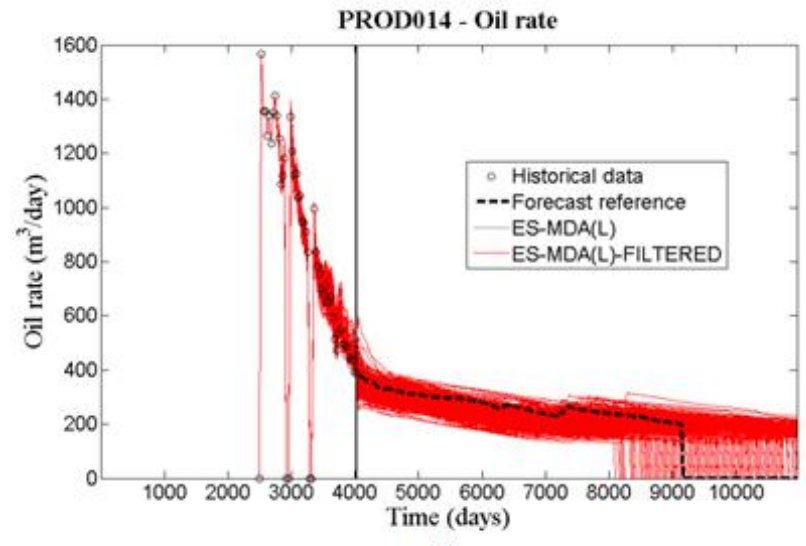

(a)

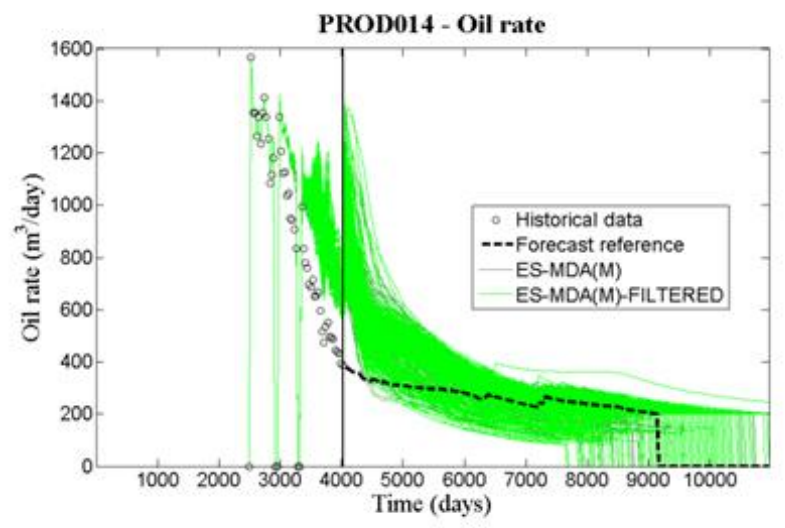

(b)

Figure 14. Oil rate forecast - PROD014: ES-MDA (L) (a) and ES-MDA (M) (b).

Figure 4 because injector wells are located at lower layers while producers are at top layers.

Before proceeding to the production forecast, we selected the accepted scenarios according to an NQDS value of 40 , i.e., each accepted scenario had absolute NQDS values lower or equal to 40 for all variables assimilated. This threshold allowed us to compare the two approaches because both of them presented scenarios respecting this condition.

Figures $13 a$ and $b$ show field cumulative oil production for ES-MDA(L) and ES-MDA(M), while Figures $13 \mathrm{c}$ and $\mathrm{d}$ plot field cumulative water production. Both approaches encompassed the reference data, but a higher variability achieved for ES-MDA(M) was due to the worst data match during the historical period, as seen in Figure 4.

Nevertheless, in a well-by-well analysis, ES$M D A(L)$ presented a much better response compared to ES-MDA (M). Figure 14 shows an example that could be generalized for most of the remaining production wells, where the scenarios from ES-MDA $(L)$ encompassed the reference data during all forecast period and generated a smoother transition between the historical and forecast period. This indicates that ES-MDA(L) generated better scenarios after the application of the methodology.

ES-MDA (L) outperformed ES-MDA (M) in all the steps of the analysis (data match, uncertainty reduction, and production forecast). These results showed that an appropriate parameterization of the petrophysical images is very relevant during data assimilation. The use of a less-appropriate parameterization, such as the zonation (ES-MDA (M)) might generate a high mismatch between historical and simulated data, while impairing the representation of the reservoir and, consequently, the production forecasts of the wells.

\section{CONCLUSIONS}

This work carried out a study assessing the main impacts of using a less-appropriate parameterization of petrophysical images by comparing the zonation technique and the distance-dependent covariance localization using ES-MDA.

When using distance-dependent covariance localization (ES-MDA (L)), we achieved good data match, geologically consistent models, and good production forecast (encompassing the reference model). However, when we used zonation (ES-MDA (M)), the results did not present the same pattern, as we observed some difficulty to honor data match, geological continuity, and production forecast.

Therefore, we have shown that the parameterization of the petrophysical images is extremely important for data assimilation and, consequently, for the development of an oil field. If we consider a less-appropriate technique, such as the zonation, we might not get a good representation of the reservoir, and this will affect the production forecast and the whole process of field development. Furthermore, data assimilation 
methods unable to handle a high number of uncertain variables or to be integrated with geostatistical techniques face additional limitations coming from the use of a less-appropriate parameterization technique, such as zonation. Our results indicate that the capability to deal with a large number of uncertain attributes and maintain geological consistency in the reservoir model are vital features of data assimilation techniques.

By explicitly highlighting how less-appropriate petrophysical images parameterization can impact the data assimilation process, this study provides support for decisions related to how to treat petrophysical images in reservoir studies.

\section{ACKNOWLEDGMENTS}

This work was conducted with the support of Petrobras and Energi Simulation within the ANP R\&D tax as "commitment to research and development investments." The authors are grateful for the support of the Center of Petroleum Studies (CEPETRO-UNICAMP/Brazil), the Department of Energy (DE-FEM-UNICAMP/Brazil), and the Research Group in Reservoir Simulation and Management (UNISIM-UNICAMP/Brazil). In addition, the authors would like to give a special thanks to CMG for software licenses, and to $\mathrm{Dr}$ Alexandre A. Emerick (from Petrobras) for providing the EHM tool to UNISIM. Helena Nandi Formentin holds CNPq Brazil scholarship (bolsista do CNPq Brasil).

\section{REFERENCES}

Aanonsen, S. I.; Nævdal, G.; Oliver, D. S.; Reynolds, A. C.; Vallès, B. The ensemble Kalman filter in reservoir engineering - A review. SPE Journal, v. 14(3), p. 393-412, 2009.

Agunwoke, G. O.; Egbele, E.; Onyekonwu, M. A Statistical approach to reservoir zonation. SPE 88962. In: $\mathbf{2 8}^{\text {th }}$ Annual SPE International Technical Conference and Exhibition, 2-4 August, Abuja, Nigeria, 2004. https://doi.org/10.2118/88962-MS

Almeida, F. L.; Formentin, H. N.; Maschio, C.; Davolio, A.; Schiozer, D. J. Influence of additional objective functions in the history matching and uncertainty reduction. SPE-190804-MS. In: SPE Europec, 11-14 June, Copenhagen, Denmark. 2018.
Avansi, G. D.; Schiozer, D. J. UNISIM-I: Synthetic model for reservoir development and management applications. International Journal of Modeling and Simulation for the Petroleum Industry, v. 9(1), p. 21-30, 2015.

Bertolini, A. C.; Maschio, C.; Schiozer, D. J. A methodology to evaluate and reduce reservoir uncertainties using multivariate distribution. Journal of Petroleum Science and Engineering, v. 128, p. 1-14, 2015. https://doi.org/10.1016/i.petrol.2015.02.003

Botechia, V. E.; Gaspar, A. T. F. S.; Davolio, A.; Avansi, G. D.; Schiozer, D. J. Investigation of production forecast biases of simulation models in a benchmark case. Oil \& Gas Science and Technology, v. 73, p.1-12, 2018.

https://doi.org/10.2516/ogst/2018014

Emerick, A. A. Analysis of the performance of ensemble-based assimilation of production and seismic data. Journal of Petroleum Science and Engineering, v. 139, p.219-239, 2016.

https://doi.org/10.1016/i.petrol.2016.01.029

Emerick, A. A.; Reynolds, A. C. Combining sensitivities and prior information for covariance localization in the ensemble Kalman filter for petroleum reservoir applications. SPE Reservoir Evaluation \& Engineering, v. 14(4), p. 443-452, 2011.

Emerick, A. A.; Reynolds, A. C. Ensemble smoother with multiple data assimilation. Computers \& Geosciences, v. 55, p. 3-15, 2013. https://doi.org/10.1016/i.cageo.2012.03.011

Evensen, G. Data Assimilation - The Ensemble Kalman Filter. $2^{\text {nd }}$ Edition. Berlin: Springer Science and Business Media, 307 p, 2009.

Gaspari, G.; Cohn, S. Construction of correlation functions in two and three dimensions. Quarterly Journal of the Royal Meteorological Society, v. 125(554), p. 723- 757, 1999.

https://doi.org/10.1002/qj.49712555417

Hutahaean, J. J.; Demyanow, V.; Christie, M. A. Impact of model parameterisation and objective choices on assisted history matching and reservoir forecasting. SPE-176389-MS. In: SPE/IATMI Asia Pacific Oil \& Gas Conference and Exhibition, 20-22 October, Nusa Dua, Bali, Indonesia, 2015.

https://doi.org/10.2118/176389-MS 
Khaninezhad, M. R.; Jafarpour, B. Sparse geologic dictionaries for field-scale history matching application. SPE-173275-MS. In: SPE Reservoir Simulation Symposium, 23-25 February, Houston, Texas, USA, 2015.

https://doi.org/10.2118/173275-MS

Maschio, C.; Schiozer, D. J. Probabilistic history matching using discrete Latin Hypercube sampling and nonparametric density estimation, Journal of Petroleum Science and Engineering, v. 147, p.98115, 2016.

https://doi.org/10.1016/j.petrol.2016.05.011

Morosov, A. L.; Schiozer, D. J. Field development process revealing uncertainty assessment pitfalls. SPE-180094-MS. In: SPE Europec, May 30 - Jun2, Vienna, Austria, 2016.

https://doi.org/10.2118/180094-MS

Oliveira, G. S.; Soares, A. O.; Schiozer, D. J.; Maschio, C. Reducing uncertainty in reservoir parameters combining history matching and conditioned geostatistical realizations, Journal of Petroleum Science and Engineering, v. 156, p. 7590, 2017. https://doi.org/10.1016/i.petrol.2017.05.003

Ranazzi, P. H.; Sampaio, M. A. Influence of the Kalman gain localization in adaptive ensemble smoother history matching. Journal of Petroleum Science and Engineering, v. 179, p.244-256, 2019. https://doi.org/10.1016/i.petrol.2019.04.079
Santos, S. M. G.; Gaspar, A. T. F. S.; Schiozer, D. J. Managing reservoir uncertainty in petroleum field development: Defining a flexible production strategy from a set of rigid candidates strategy, Journal of Petroleum Science and Engineering, $v$. 171, p. 516-528, 2018.

https://doi.org/10.1016/i.petrol.2018.07.048

Silva, V. L. S.; Emerick, A. A.; Couto, P.; Alves, J. L. D. History matching and production optimization under uncertainties - Application of closed-loop reservoir management, Journal of Petroleum Science and Engineering, v. 157, p.860-874, 2017. https://doi.org/10.1016/i.petrol.2017.07.037

Soares, R. V.; Maschio, C.; Schiozer, D. J. Applying a localization technique to Kalman gain and assessing the influence on the variability of models in history matching, Journal of Petroleum Science and Engineering, v. 169, p.110-125, 2018. https://doi.org/10.1016/i.petrol.2018.05.059

Soares, R. V.; Maschio, C.; Schiozer, D. J. A novel localization scheme for scalar uncertainties in ensemble-based data assimilation methods. Journal of Petroleum Exploration and Production Technology, v. 9(4), p. 2497-2510, 2019. https://doi.org/10.1007/s13202-019-0727-5 